\title{
THERMAL COMFORT ANALYSIS IN OFFICE BUILDINGS WITH DIFFERENT AIR-CONDITIONING SYSTEMS
}

\author{
J. SZABO ${ }^{\text {a }}$ L. KAJTAR ${ }^{\mathrm{b}}$ \\ Department of Building Service and Process Engineering, Budapest University of Technology and Economics, \\ H-1111 Budapest, Müegyetem rakpart 3-9, Hungary \\ a E-mail: szaboj@epget.bme.hu \\ bE-mail: kajtar@epget.bme.hu
}

\begin{abstract}
It is a prime aim to ensure a suitable comfort level in case of office buildings. The productivity of office employees is directly influenced by the comfort. Thermal discomfort and poor indoor air quality deteriorate the intensity and quality of human work. We investigated the comfort in office buildings with on-site measurements during the summer season. The office buildings were operating with different HVAC (Heating, Ventilating and Air-Conditioning) systems: ducted fan-coil with suspended ceiling, installation, non-ducted fan-coil with floor-mounted installation, active chilled beam with fresh air supply.

We evaluated the thermal comfort under PMV (Predicted Mean Vote), PPD (Predicted Percentage of Dissatisfied), the local discomfort based on DR (Draught Rate) and the IAQ (Indoor Air Quality) based on carbon dioxide concentration. The comfort measurements were evaluated. The measurements were evaluated with scientific research methods, comfort categories based on the requirements of CR 1752. The results of this comparison were presented in this article.
\end{abstract}

Keywords: thermal comfort, $P M V$, PPD, carbon dioxide concentration, draft rate

\section{Introduction}

Fourty percent of the total energy consumption is generated by the energy consumption of buildings. Within this, air conditioning represents a significant proportion. There is a need to reduce energy consumption and increase comfort at the same time [1,2]. The thermal sensation may play an important role especially in office buildings because thermal discomfort deteriorates human productivity $[3,4]$. Reducing the energy consumption cannot be at the expense of comfort, so it is a task to continuously control the comfort according to international practice $[5,6]$. The comfort of the air-conditioned spaces can be characterised by the measurement and evaluation of the interior air state characteristics.

Continuous measurement requires a programmed measuring and data logger system. For the data processing and evaluation we developed a new measuring system assembly and a personally developed compu- tational program. Parameters can be evaluated based on probability theory as discrete random variables. The rating of comfort according to comfort categories (CR 1752, EN 15251) is based on the $95 \%$ confidence range of the measured and calculated values.

On-site measurements were carried out in several office buildings, we evaluated comfort according to comfort categories. The tests were carried out in different spaces with different-air conditioning systems:

- ducted fan-coil with suspended ceiling installation,

- non-ducted fan-coil with floor-mounted installation,

- active chilled beam.

The air-conditioning systems of office buildings have already been adjusted and commissioned.

In this article we present the measurement method, evaluation methodology and the results obtained with each air-conditioning system.

This is an open-access article distributed under the terms of the Creative Commons Attribution-NonCommercial 4.0 International License (https://creativecommons.org/licenses/by-nc/4.0/), which permits unrestricted use, distribution, and reproduction in any medium for non-commercial purposes, provided the original author and source are credited, a link to the CC License is provided, and changes - if any - are indicated. 


\section{Methods}

\subsection{Measurement}

On-site measurements were carried out in three office buildings with different HVAC systems: ducted fancoil with suspended ceiling installation, non-ducted fan-coil with floor-mounted installation and active chilled beam system. The series of measurements were made in the summer period, which is critical for comfort and air-conditioning [5-7]. The measured physical characteristics and their sampling frequency are shown in Table 1.

Eight-twelve units of measuring rods with air temperature and humidity instruments and data loggers were installed in the office building. To measure the turbulence and the draught rate, two instrument clusters were assembled to provide the air velocity measurement for the required frequency (2 seconds) and the air velocity range $(0.01-0.25 \mathrm{~m} / \mathrm{s})$ in the occupied zones. Every 3-5 days the measuring systems have been installed in different oriented single and landscaped offices. A well-founded evaluation could be carried out based on the results of 2-4 weeks of measurement in a building. It is apparent that 120,000-160,000 data had to be received, stored, processed and evaluated daily according to the data of Table 1.

\subsection{Evaluation}

Each characteristic of the thermal comfort in the enclosed space (air temperature, humidity, mean radiation temperature, mean air velocity, turbulence intensity) is probability variable. Their value can be characterised corresponding to mean value, standard deviation, confidence interval, etc. $P M V, P P D, T u$ and $D R$ parameters have been used for the assessment of comfort applied in international practice [8-10]. We can obtain a representative quantitative image of the given comfort space by determining the statistical characteristics after evaluating the measured data of comfort assessments. The measurement results were processed and evaluated based on the $95 \%$ confidence interval, comparing the requirements of comfort categories (in this case the CR 1752) [11, 12]. We have developed a theoretical model and a software tool for the comfort analysis to the efficient and quick execution of the calculation algorithm [13-15].

\section{Results}

\subsection{Thermal comfort (Fig. 1)}

From the thermal comfort point of view, the best result was given by the ducted fan-coil with suspended ceiling installation system (category " $>C$ " $11.1 \%$ ), while the least favoured result was given by the non-ducted fan-coil with floor-mounted installation system (category ">C" $55.6 \%$ ).

\subsection{Draught rate (Fig. 2)}

From the draught rate point of view, the best result was given by the active chilled beam system (category "A" $90.3 \%$ ).

\subsection{Air temperature (Fig. 3)}

From the air temperature point of view, the best result was given by the active chilled beam system (category "A" $38.6 \%$ ).

\subsection{Carbon dioxide concentration (Fig. 4)}

From the thermal comfort point of view all systems achieved a very high level of comfort. The results for the category " $A$ " were $73.7 \%-100 \%$.

Table 1. The measured parameters

\begin{tabular}{lccc}
\hline & Measured parameter & Sign & Sampling frequency \\
\hline Air temperature & $t_{a}$ & $5 \mathrm{~min}$ \\
Globe temperature & $t_{g}$ & $5 \mathrm{~min}$ \\
Relative humidity & $f$ & $5 \mathrm{~min}$ \\
Air velocity & $v_{a}$ & $2 \mathrm{sec}$ \\
Carbon dioxide concentration & $c_{\mathrm{CO}_{2}}$ & $5 \mathrm{~min}$ \\
\hline Chilled beam / & Entering - cooling water temperature & $t_{w e}$ & $5 \mathrm{~min}$ \\
fan-coil & Leaving - cooling water temperature & $t_{w l}$ & $5 \mathrm{~min}$ \\
\hline $\begin{array}{l}\text { Air handling } \\
\text { unit }\end{array}$ & Supply air temperature & $t_{s a}$ & $5 \mathrm{~min}$ \\
\hline
\end{tabular}




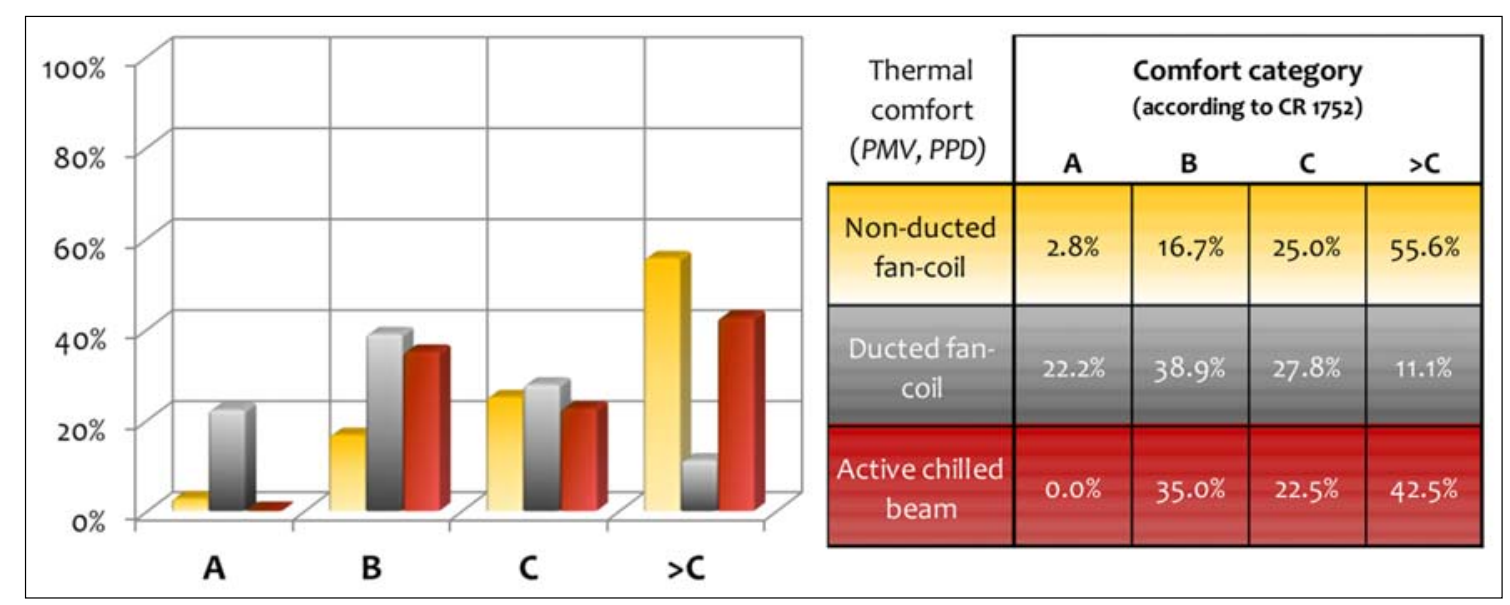

Fig. 1. The category distribution of thermal comfort measurements

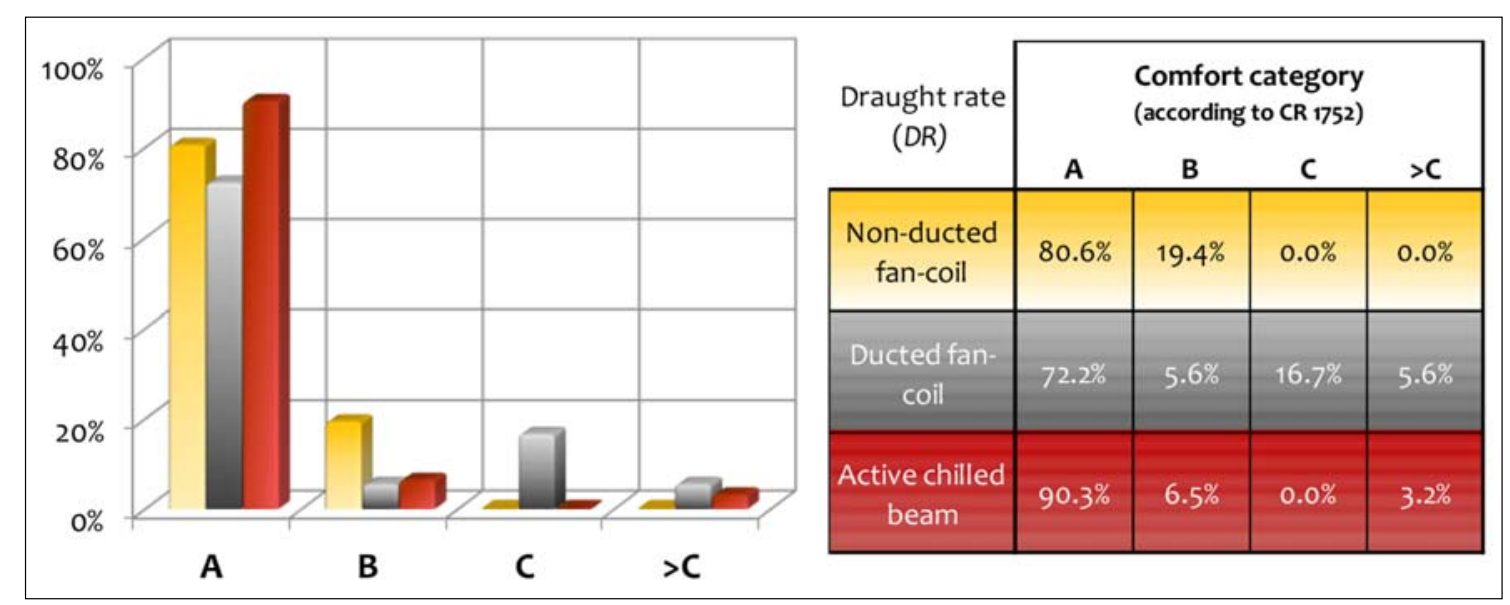

Fig. 2. The category distribution of draught rate measurements

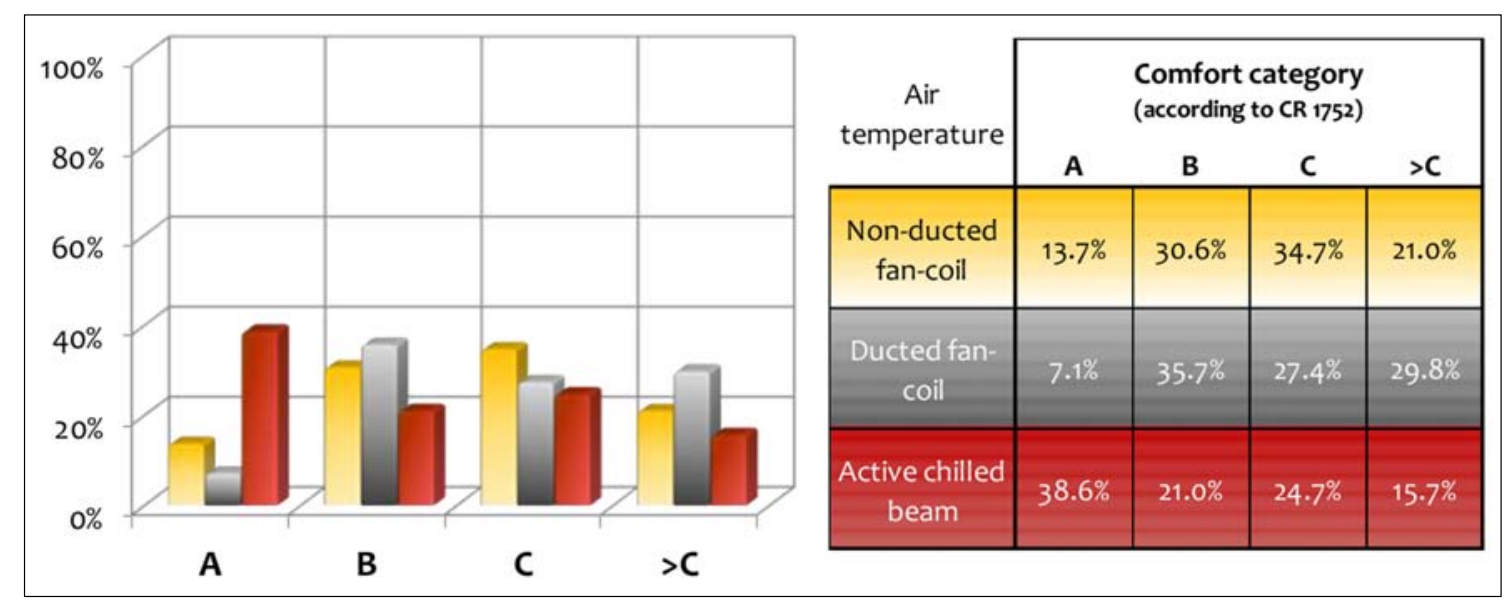

Fig. 3. The category distribution of air temperature measurements

\section{Conclusions}

Based on the results obtained, it is possible to assess the comfort parameters according to the individual categories. We can draw the following conclusions from the comfort parameters point of view:
- It is most difficult to ensure the highest level of category "A" expectations from the thermal comfort point of view (category "A" $0.0 \%-$ $22.2 \%)$.

- More favourable situation in terms of the air temperature (category " $\mathrm{A}$ " $7.1 \%-37.4 \%$ ). 


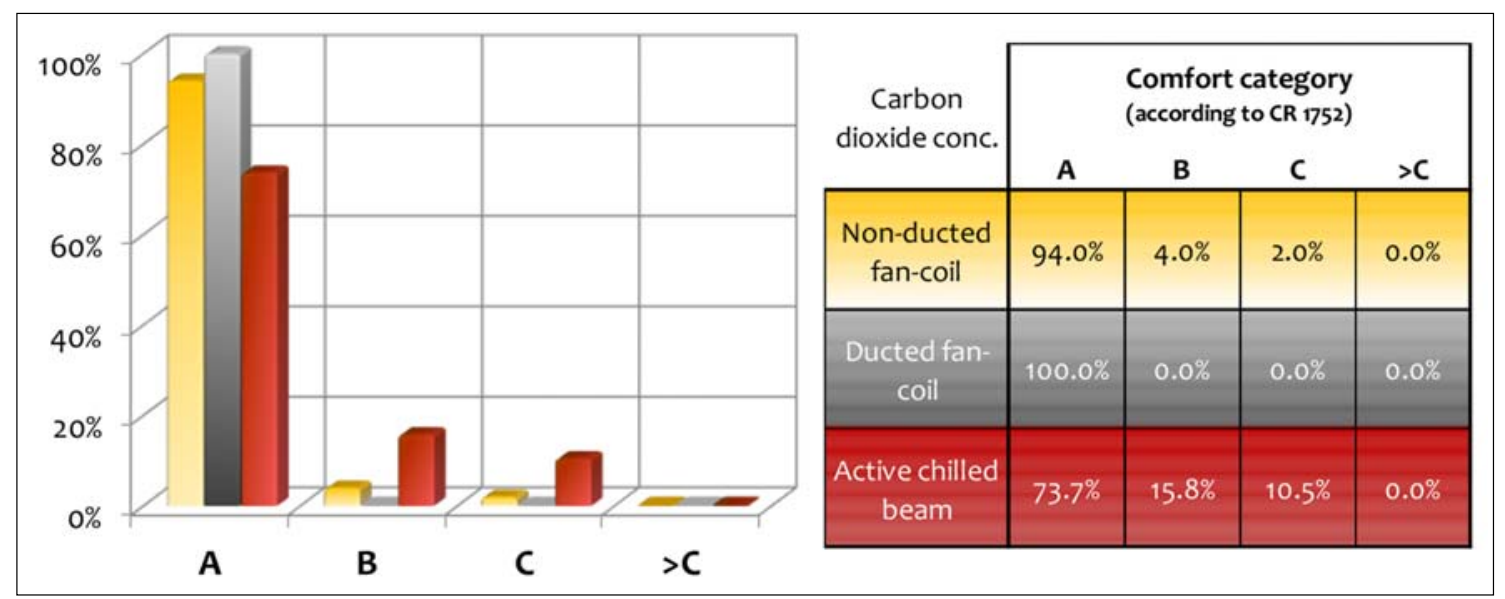

Fig. 4. The category distribution of carbon dioxide concentration measurements

- The results are even better in case of draught rate (category "A" $72.2 \%-90.3 \%$ ).

- Comfort studies have shown that considerably better comfort categories for carbon dioxide concentrations (category " $\mathrm{A}$ " $73.7 \%-100 \%$ ) can be achieved, such as thermal comfort, draught rate and air temperature. The differences between the individual systems are also small. This is due to the fact that the carbon dioxide concentration depends essentially on the amount of fresh air, less on the type of air-conditioning system (if the proper air handling system is in the comfort room). The fresh air rate was $40-45 \mathrm{~m}^{3} / \mathrm{h}$ in the buildings.

It is also possible to evaluate the types of air-conditioning systems based on the results obtained. The climate control system can provide the best comfort for the draught rate and the air temperature. The design and implementation of the chilled beam system is a more complex task, the design of the cooling system differs from conventional fan-coil systems [16, 17].

The results of measurements gave assistance to the planning and can help to improve the regulation of HVAC (Heating, Ventilating and Air-Conditioning) systems.

\section{References}

[1] Fanger P. O. (1967), Calculation of thermal comfort: introduction of a basic comfort equation. ASHRAE Trans. 73, III.4.1-III.4.20.

[2] Croome D. J., Gan G., Awbi H. B. (1993), Thermal comfort and air quality in offices. Indoor Air, Helsinki, 6, 3742.

[3] Kosonen R., Tan F. (2004), Assessment of productivity loss in air-conditioned buildings using PMV index. Energy and Buildings, 36(10 spec. iss.), 987-993.
[4] Lan L., Wargocki P., Lian Z. (2011), Quantitative measurement of productivity loss due to thermal discomfort. Energy and Buildings, Vol. 43(5 spec. iss.), 1057-1062.

[5] Erdősi I., Kajtár L., Bánhidi L. (1997), Thermal comfort in climatized office buildings. Washington, USA. Healthy Buildings Conference. Proceedings Vol. 2, pp. 207-213.

[6] Erdősi I., Kajtár L., Bánhidi L. (1998), Thermal comfort in climatized office building in winter. Atlanta, USA. Design, Construction and Operation of Healthy Building/ ASHRAE, pp. 179-185.

[7] Kajtár L., Leitner A. (2007), High Quality Thermal Environment by Chilled Ceiling in Office Building. 9th REHVA World Congress Clima "Well-Being Indoors", Helsinki, 6 p.

[8] van Hoof J. (2008), Fourty years of Fanger's model of thermal comfort: comfort for all. Indoor Air Journal, 18, 182-201.

[9] Howell W. C., Kennedy P. A. (1979), Field validation of the Fanger thermal comfort model. Hum. Factors, 21, 229-239.

[10] van Hoof J., Hensen J. M. L. (2007), Quantifying of relevance of adaptive thermal comfort models in moderate thermal climate zones. Building and Environment, 42, 156-170.

[11] CR 1752 (1999), Ventilation for buildings - Design criteria for the indoor environment Bruxelles: European Committee for Standardisation.

[12] CEN Standard EN 15251 (2007), Indoor environmental input parameters for design and assessment of energy performance of buildings addressing indoor air quality, thermal environment, lighting and acoustics Bruxelles: European Committee for Standardisation.

[13] ISO 7730:2005(E), Ergonomics of the thermal environment - Analytical determination and interpretation of thermal comfort using calculation of the PMV and PPD indices and local thermal comfort criteria. Geneva: International Standards Organization, 2005.

[14] ASHRAE Standard 55-04 (2004), Thermal Environmental Conditions for Human Occupancy, Atlanta, American Society of Heating Refrigeration and Air-conditioning Engineers. 
[15] CIBSE (2006), CIBSE Guide A chapter 1: Environmental criteria for design. London, Chartered Institution of Building Services Engineers.

[16] Kajtár L., Bánhidi L., Bakó-Bíró Zs. (2001), Thermal and air quality comfort in the Hungarian office buildings. Mi- ami Beach, USA. Proceedings of the Second NSF International Conference on Indoor Air Health, pp. 270-278.

[17] Nyers J., Pek Z. (2014), Mathematical Model of Heat Pumps' Coaxial Evaporator with Distributed Parameters. Acta Polytechnica Hungarica, 11(10), 41-54. 